\title{
Protecting expatriates in hostile environments: Institutional forces influencing the safety and security practices of internationally active organisations
}

Authors:

- Anthony Fee (University of Technology Sydney, UTS Business School) anthony.fee@uts.edu.au

- Susan McGrath Champ (The University of Sydney, The University of Sydney Business School) susan.mcgrathchamp@sydney.edu.au

- Marco Berti (University of Technology Sydney, UTS Business School) marco.berti@uts.edu.au

The operations of internationally active organisations continue to encroach on hostile locations that are vulnerable to the negative consequences of crises such as political upheaval, terrorist attacks, or natural disasters. Yet research into how firms ensure the physical and psychological safety and security of international staff in these locations is limited. This article reports an empirical study exploring the expatriate safety and security practices of 28 internationally active organisations from three industries that commonly operate in hostile environments. We unveil starkly different approaches across the three industries, and label these approaches 'regulatory' (mining and resources), 'informal mentoring' (news media), and 'empowering' (international aid and development). We use institutional theory to propose that these configurations reflect legitimacy-seeking choices that these organisations make in response to the various institutional environments that affect each sector. Our results provide a platform for initial theory building into the interrelated elements of organisations' safety and security practices, and the institutional factors that shape the design of these.

Key words: Expatriate, hostile environment, human resource management, international assignments, safety and security, institutional theory, expatriate safety, crisis 
Creating a global workforce brings benefits but comes with costs. International mobility increases exposure of expatriates to threats that range from individual misadventure to terrorist attacks (e.g. Claus, 2009; Czinkota, Knight, Liesch, \& Steen, 2010). These threats are becoming more salient to organisations with operations in multiple countries ('internationally active organisations') as the number of expatriates working in locations which present substantial danger to health and security grows (Bader, 2014).

This article reports an empirical investigation that identifies and explains the characteristics of the expatriate safety and security approaches of internationally active organisations from three industries, all operating in particularly dangerous environments. We examine this phenomenon through the lens of institutional theory, a perspective that foregrounds the influence of the institutional environments in which organisations configure and enact their HR practices, and the various stakeholders that legitimise those institutions. Our research builds on recent empirical studies that have begun to unpick the HR implications of expatriates' safety and security in particular sectors (Fee \& McGrath-Champ, 2016) and settings (Bader \& Schusterb, 2015). Further, we contribute towards theory development by documenting similarities and differences across the three sectors, and offer propositions for understanding how institutional pressures may contribute toward this pattern of practices. Our study is the first, to our knowledge, to apply an institutional perspective to the HR practices of internationally active organisations in hostile environments. This sample represents an interesting case of organisational activity occurring at the intersection of different institutional fields. Until recently, institutions have been conceptualised as relatively independent social arenas, thus underplaying the relations linking different fields (Furnari, 2016). However, organisations operating in alien settings must negotiate institutional logics of home, host and sectoral environments. Substantial differences between these discursive realms increase complexity and can prompt new 
configurations at myriad levels, including the potential of 'outsider driven' institutional change (Maguire \& Hardy, 2009, p. 148). Indeed, our results suggest a range of institutional forces that contain remnants of different organisational fields shape these organisations' practices and philosophies: home country, host country, and specific industry. Underpinning this theoretical contribution is our aim to better understand internationally active organisations' responses to the HR challenges of operating in hostile environments. In doing so, we approach HR management as a devolved set of practices that extend beyond the confines of the HR function (Kulik \& Bainbridge, 2006) to include those critical HR services and activities undertaken by operational staff and line managers.

We commence by summarising the theoretical landscape of institutional theory, and the existing empirical base from which our research questions are developed. This is followed by coverage of the methodology and results of our exploratory study. We conclude by using institutional theory as a lens through which to discuss the implications for international human resource practitioners and researchers.

\section{Theory and literature}

We define a hostile environment to include any environment perceived to be vulnerable to events or circumstances that present a threat to expatriates' safety and security (McPhail \& McNulty, 2015). At least three types of distinct threats exist. First, myriad natural or medical emergencies tend to be indiscriminate in whom they affect (e.g. typhoons, medical emergencies like Zika or Ebola outbreaks). Organisations can cushion expatriates to some extent against these threats (e.g. prophylactic agents); however preventing or responding to such threats is contingent to a large extent on local conditions and institutions (health, education) and so are, to a large extent, infrastructure-dependent. A second type of threat involves direct and indirect targeted criminal 
and political violence. Such threats are more legitimacy-dependent in that they may relate directly to the way in which local actors perceive expatriates and their employers; e.g. targeted kidnappings of foreigner workers in Nigeria in June 2016 (Cuddihy, 2016). A third and related category of risk emerges from expatriates' contextual or cultural ignorance and incompetence (knowledge-dependent threats). While these are untargeted, expatriates' lack of awareness of, or experience in, the host-country, can amplify exposure to and consequences of threats that range from climatic (e.g. dangers to health of particular weather conditions or events) to cultural (e.g. hostility arising from breaching cultural mores) to specific contexts (e.g. risks posed by particular road conditions). In general, hostile environments provide conditions that make all three types of crises more frequent and/or potentially more severe.

Researchers examining the way organisations 'manage' threats from their external environment have catalogued a range of generic checklists, guidelines and tools to assist organisations plan or coordinate crisis response (e.g. Bernstein, 2011). From this, researchers have distilled several elements that are central to ensuring expatriate safety and security (Fee, McGrath-Champ, \& Liu, 2013), including developing robust policy frameworks, evaluating threats, establishing processes and know-how for managing crises, and providing training, resources and post-crisis support for affected staff. A comprehensive study of the HR practices of internationally active organisations from the international development sector showed that their approaches were centred on strong organisational cultures supported by a suite of HR practices and competencies (Fee \& McGrath-Champ, 2016). A feature of these organisations was their use of elements of 'acceptance' within the local community as a means to buffer expatriates against threats, apparently in contrast to approaches preferred by corporate multinationals (Harvey, 1993). The authors suggested that future studies examine the extent to which this configuration of practices might be comparable with and/or transferable to other sectors (Fee \& McGrath-Champ, 
2016). Hostile environments provide an especially valuable context for this because, by definition, they present elevated threats to staff as well as distinct institutional environments that influence organisations' operations. In this context, 'institutions' are the assorted internal and external structures and practices that collectively create stability and meaning (Scott, 1995) and which constitute the 'rules' in which organisations operate. Directly and indirectly, these can be sources of threat or protection to international staff and can place myriad demands on the ways in which expatriate safety and security is managed.

To understand how and why the practices of internationally active organisations, including HR policies and practices, interact with their external environments in the ways that they do, we draw on institutional theory (DiMaggio \& Powell, 1983; Greenwood, Oliver, Sahlin, \& Suddaby, 2012; Lepoutre \& Valente, 2012). Institutional theory posits that organisations face pressure to conform in order to attain or retain legitimacy within a given institutional context, characterised by sets of 'cognitive, normative, and regulative elements' that have become accepted as taken for granted facts (Maguire \& Hardy, 2009, p. 149). Organisational legitimacy (Suchman, 1995) refers to the acceptance of the organisation by the prevailing institutions and its social actors (Kostova \& Zaheer, 1999). The legitimacy of an organisation's practices is seen as central to its success within a particular environment. Researchers argue that this process of firms seeking legitimacy leads to institutional homogeneity, as organisations feel pressure to adopt norms, copy, or respond to external pressure to be more alike via a process of 'isomorphism.' Three distinct isomorphic pressures have been articulated (DiMaggio \& Powell, 1983): coercive isomorphism stems from the need to comply with social rules and regulations, notably 'institutional agencies' present in the organisational environment (Westney, 1993, p. 49); mimetic isomorphism results from implicit pressures to imitate or innovate as a result of competition from other organisations within the field, and normative isomorphism derives from the 
professionalisation of labour creating a 'pool of almost interchangeable individuals who occupy similar positions (...) and possess a similarity of orientation' (DiMaggio \& Powell, 1983, p. 152). Empirical studies have shown that isomorphism helps to legitimate an organisation in the eyes of both regulators and the public (Deephouse, 1996), and the concept is often used to examine the diffusion of homogeneous human resources practices (Gooderham, Nordhaug, \& Ringdal, 1999; Rosenzweig \& Nohria, 1994; Zhang et al., 2016). It therefore offers a solid theoretical lens for understanding similarities in the practices of organisations that operate in the same institutional environment. That is, it enables our research to go beyond descriptive accounts of expatriate protection measures that earlier studies have reported (Fee \& McGrath-Champ, 2016) to explain pattern of practices.

Institutional theory acknowledges the socially constructed nature of concepts like 'safety' and 'hostility' (Gherardi, 2006; Gherardi \& Nicolini, 2000). From this perspective, organisations do not simply devise strategies to suit a set of objective environmental threats, as contingency theory would predict (Donaldson, 2001). Rather, organisations co-produce a process involving 'people, technologies, and textual and symbolic forms assembled within a system of material relations' (Gherardi \& Nicolini, 2000, p. 10). In such a process legitimacy issues are central to organisational practices (Lindøe, Engen, \& Olsen, 2011).

Understanding these practices in internationally active organisations is especially pertinent given the diverse layers of institutions that shape their operations (Kostova, Roth, \& Dacin, 2008). These include national institutions in parent- and host-countries, as well the organisational fields existing within an industry (Kostova et al., 2008). On the one hand, the importance of legitimacy for internationally active organisations is exacerbated by the substantial barriers that they must overcome; notably, liability of being 'foreign' (Kostova et al., 2008). At the same time, informal institutional forces like cultural, linguistic and geographic barriers, and 
the diversity of legitimating bodies, may impede legitimation efforts (Kostova \& Zaheer, 1999). The result is that these organisations' responses to their institutional environments are 'unique and unpredictable' (Kostova et al., 2008, p. 999).

For organisations that operate in hostile international environments, legitimacy pressures feed directly into issues associated with expatriate safety and security. By definition, hostile environments tend to be characterised by weak formal institutions in the guise of poorly enforced rules of law, unreliable infrastructure, high levels of political instability, and low levels of economic development (Institute for Economics and Peace, 2014). Against such a backdrop, legitimacy from host institutional actors in the form of support for an organisation's operations and acceptance of international staff within a host community can provide a 'safety net' for expatriates through access to information and physical and emotional support. Indeed, such an acceptance approach has been shown to be a viable alternative to more defensive protection strategies that separate expatriates from host actors (Fee \& McGrath-Champ, 2016). This form of legitimacy builds on cognitive and normative acceptance that tend to be more 'tacit' and thus potentially problematic than (formal and explicit) regulatory institutions (Kostova \& Zaheer, 1999).

Viewed holistically, hostile environments present organisations with formal institutions that may be unreliable and social actors that may be sources of either threat or protection. These factors elevate the need for legitimacy to ensure expatriates are protected from indiscriminate or targeted threat. However, the empirical and theoretical literature provides little guidance; indeed, it suggests forces of convergence and divergence may operate simultaneously on the way in which expatriates might be protected. On the one hand, the weak formal institutions may provoke similarly abundant practice among organisations irrespective of their internal characteristics or industry. In these cases we would expect to find evidence of firms deploying a suite of common 
'good practice' solutions to protect expatriates that are designed to offset the uncertainties and institutional weaknesses prevalent in hostile locations. On the other hand, industry-level demands and entrenched norms may lead to different responses being used in particular sectors (Bjerkan, 2010; Watson, 2005), even in identical host-institutional environments. Irrespective, the few studies in business and management in this domain remain directed at expatriates' work attitudes and performance (Bader, 2014; Bader \& Berg, 2013) rather than how organisations can protect expatriates' physical and psychological safety. Consequently the ways in which the various institutional forces influence policies and practices of internationally active organisations in hostile environments remains poorly mapped.

The empirical research reported here takes steps to remedy the soft empirical and theoretical underbelly of this phenomenon by examining how these competing institutional forces influence the HR practices of internationally active organisations. We do this by examining the deployment of practices and philosophies for managing expatriate safety and security by organisations from three sectors conditioned to operating in hostile environments.

\section{Methodology and research context}

The study used an inductive (interpretivist) research design. This approach is suited to studying phenomena with limited empirical foundations because it avoids the potentially misleading descriptions and conceptual models that deductive (positivist) research might produce (Edmondson \& McManus, 2007; Von Krogh, Rossi-Lamastra, \& Haefliger, 2012). Our aim was to produce robust empirical foundations that would allow propositions about explanatory relationships between variables to be generated for future testing or refutation.

We approached this task via a multiple case design, centred on examining 'extreme' cases (Farquhar, 2012) in the form of organisations with vast experience operating in hostile 
environments. Case study research has a long tradition in business and management research (Farquhar, 2012). While not associated with a particular epistemology, our interpretivist perspective was consistent with theory-building research drawing on observations in situ (Dul \& Hak, 2008), seen to be one of the strengths of the approach (Yin, 2003).

\section{Sample}

The sample comprised twenty-eight internationally active organisations from industries that commonly operate in hostile environments: (a) mining and resources (M\&R, 12 organisations), (b) news media (media, 6 organisations), and (c) international aid and development (IAD, 10 organisations). Combined, the case study organisations had assignees in more than 31 nations rated by the risk consultancy firm Control Risks as being a high or extreme risk threat.

Case selection involved a combination of purposive and convenience sampling drawing mainly on the authors' professional contacts, supplemented by snowball sampling and - in a minority of cases - direct approaches. We sought cases that would provide diversity in terms of variables like parent country, size, and type, remaining cognisant of the pragmatic need to access a suitable depth of data regarding the phenomenon (Gerring, 2007). Table 1 profiles the 28 organisations as well as the breadth and extent of data collected.

INSERT TABLE 1 ABOUT HERE

\section{Research context}

The operating conditions, objectives, and nature of expatriate placements being managed by the case study organisations varied within and across sector. M\&R organisations are increasingly operating in inherently unstable 'frontier' regions in order to access available and cheap natural resources. However, their exposure to threat is imbued by the nature of $M \& R$ work irrespective 
of destination - e.g. capital intensive and highly hazardous via the use of potentially dangerous plant and chemicals. Organisations in this sector tend to have high levels of standardisation and tightly-coupled systems, characterised by invariant sequences leading to production goals (Perrow, 2011). The sector also experiences high levels of resentment and mistrust from local communities, manifest through a series of recent legitimacy-dependent threats directed at local and international workers (Newenham-Kahindi, 2011). In most nations the licence to operate for organisations requires stringent safety standards. These organisations use expatriates for myriad roles, from highly-skilled (management, engineering) to semi-skilled (e.g. machinery operators). It is common for expatriates in various roles to be co-located on-site. Indeed, a feature of most (not all) M\&R placements is their geographic remoteness and fixedness; that is, the work usually revolves around fixed sites defined by access to natural resources.

In contrast, the media's use of expatriates tends to be via small numbers of foreign correspondents and special event reporters. The role requires high levels of mobility and so their work 'space' encompasses site visits, frequent ground or air travel, and make-shift offices. It also involves a high degree of reliance on the local knowledge and contacts of host-country national $(\mathrm{HCN})$ informants, technicians and staff. Expatriates tend to operate in-country alone or in small teams (e.g. correspondent, producer, camera operator). On the whole, their relative mobility and the nature of events they cover in hostile environments (i.e. natural disaster, war) provide opportunities to interact regularly with expatriates from their profession. In this loosely-coupled context, strategies, policies, employees' decisions and outcomes are linked while still preserving elements of independence and indeterminacy (Orton \& Weick, 1990). As a consequence the influence of others within this informal 'community of practice' (Wenger, 2000) is strong, relative to directions from a distant parent organisation. 
The nature of IAD placements varies greatly. Some circumstances require teams of tightly-knit expatriates operating in temporary shelter for limited periods (e.g. emergency relief), while others involve large numbers of dispersed individuals embedded in host-country organisations (typically longer-term development-focused projects). Importantly, the capacity development objectives of this sector usually require collaboration and cooperative partnerships with local communities (Cornwall \& Brock, 2005), necessitating high levels of interaction (and interdependence) with HCNs. Consequently, IAD expatriates are likely to be conditioned both by the policies and directives of host organisations and by the broader community of practice (incorporating local agencies and members of other IAD organisations) to which they belong.

All three sectors used a range of casual and permanent staff (as well as external contractors, excluded from our analysis). Placements generally ranged from 6-24 months, although all sectors made use of more flexible assignment designs (e.g. dispatching large numbers of short-term expatriates to cover major events, fly-in-fly-out placements). A mix of internally and externally recruited expatriates was common in all sectors.

\section{Data collection}

Empirical materials were collected via two complementary sources: (a) in-depth interviews with internal stakeholders, and (b) various internal policy documents.

Interviews. Interviewees included international HR managers, line managers, security experts, and expatriates (Table 1), all with at least three years' experience in the organisation. In total, 27 internal stakeholders from 15 of the sample organisations were interviewed. Interviews lasted from 45 to 120 minutes. While questions were customised to the specific experiences of interviewees, a standard interview 'template' was used, with questions relating to interviewees' roles, responsibilities, and experiences at the pre-, during- and post-crisis stages. All interviews 
except one were recorded and later transcribed in full. Notes were taken at all interviews and cross-referenced with transcripts.

Policy documents. We analysed 172 separate policy documents from 24 of the 28 organisations (Table 1). These exceeded 1000 pages in total and included codes of 'best practice', security charters, country-specific security briefings, training programs and activities, travel protocols, evacuation hierarchies, flow charts, risk rating systems, and procedures for safe travel.

\section{Data analysis}

Content analysis of documents and transcripts involved a process of coding, categorising, and comparison. Multiple cases from multiple sectors allowed us to examine the phenomenon in different settings and compare policies and practices across organisations and across industries.

The analytical process comprised four stages adapted from Farquar (2012). First, data were coded to descriptive categories in order to create tabulated case files for each organisation. These ranged from 5 to 17 pages and contained a summarised, cross-referenced catalogue of organisations' activities across stage (pre-, during and post-crisis), participants (actors involved and/or affected), and data source, as well as holistic case notes. This initial within-case analysis triangulated interview and document data and was built primarily on a priori codes.

Next, second-level thematic categories were sketched through a process of open and axial coding focusing on prominent and repeated themes. By way of example, activities relating to collecting and managing information were identified across all stages of the crisis lifecycle and so were mapped for each of the 28 organisations along three dimensions: environmental scanning, staff profiling, and incident reporting.

Once a complete set of case files was built, cross-case pattern searches were used to compare and contrast themes. This was done at multiple levels - within and across cases and 
sectors, between interviewees' experiences and written policies, and between our summarised case files and the original data. This process necessitated some follow up communications with interviewees to confirm detail. It involved the creation of numerous tables and matrices, several of which quantified or categorised the presence, extent and type of HR practices by organisation and sector. It was from these tables that several overarching assertions were devised at the sample- and industry-levels, and compared against individual case notes. Finally, our results were confirmed through member checks (Seale, 1999).

\section{Results}

Our analysis unearthed a number of patterns that provide the basis for theory development. Most prominently, we identify strong within-sector similarities regarding approaches to managing expatriate safety and security, to the point where clear philosophical distinctions existed between the three sectors. Indeed, our analysis showed that for these organisations it was sector, rather than organisation size, parent or host country, number of expatriates, or years of operation, that defined differences in their philosophical approach to managing expatriate safety and security. This led us to develop a nomenclature, expanded below, to convey the clear sectoral tendencies that emerged empirically. At the same time, we also identify some underpinning principles that appear common to all 28 organisations irrespective of sector, suggesting that 'core' practices were deemed necessary for all hostile-exposed organisations irrespective of the industry in which they operate.

These similarities and differences are summarised in Tables 2 and 3 and elaborated below.

INSERT TABLES 2 and 3 ABOUT HERE

\section{Core principles that foreground local responsiveness and context}


Viewed holistically, the data show that all 28 organisations took seriously the human - not just the business - implications of operating in hostile destinations. All invested time and resources beyond 'standard' duty of care concerns (Claus, 2010). All exceeded what is suggested in the literature in areas ranging from training (Chien \& Law, 2003) to policy development (Crandall, Parnell, \& Spillan, 2010) and post-crisis support (Raphael, 1986). Also commonplace was investment in strategic redundancy (e.g. multiple communication channels and/or information sources), and in-housing activities like post-crisis psychological support which are typically outsourced (Claus, 2010).

As exemplars of this comprehensiveness, we focus on three features prioritised at multiple stages of the expatriate management process by the sample organisations: (1) the information intensity of their expatriate support mechanisms, (2) the investment in customising policies and practices to suit on-the-ground conditions, and (3) the degree of (within-sector) collaboration and information sharing, to the extent where collaboration tended to take precedence over competition.

1. Information intensity: Prominence was placed on collecting and managing quality and timely information relating to conditions in which expatriates were operating. This involved triangulating information from multiple related activities. Ongoing 'environment scanning' was used to evaluate perceived threats - both indiscriminate and targeted, emanating from the local environment - via safety/security updates from a diverse mix of sources including publicly available media (e.g. CNN, Global Disaster Alert and Coordination System website), contracted security analysts, personal contacts (e.g. military, security or embassy personnel), in-country operatives, and local and expatriate staff. In the M\&R sector where funding was abundant, nearly half the organisations sustained the substantial cost of contracting multiple external security firms to supplement information updates. In IAD and media organisations, where resources were more 
limited, accessing experts more typically involved personal contacts, freely available information, and trained on-the-ground personnel including expatriates themselves. The bulk of organisations across all three sectors also maintained comprehensive electronic databases to collate information on incidents and individuals (although mechanisms to review this data were more sporadic).

The priority given to information extended to the use of internal experts as a clearinghouse to manage and interpret data, a practice seldom used in multinational corporations (Claus, 2011). This typically comprised small teams of security specialists and/or regional security managers based at head office, although at least four organisations from the M\&R sector also deployed in-country security experts (less common in IAD and media).

2. Customising practices: A second characteristic of all 28 organisations was a commitment to customising expatriate safety and security plans to take account of on-the-ground conditions. All organisations provided compulsory in-country security briefings of varying durations, customised to anticipated threats, placement type and specific locations. Recruitment and selection processes (e.g. psychological and physical screening), evacuation triggers and procedures, communication devices and protocols, alert notifications, and incident monitoring and reporting all underwent substantial and expensive customisation to suit specific host conditions (not just risk ratings).

We heard of several cases in which in-house security experts made country risk evaluations that differed from the formal advice provided by home governments (an issue of great sensitivity for some interviewees). By way of example, organisation R11 produced a 70page safety and security plan for one West African country. The plan includes six discrete evacuation plans for various circumstances using different air, land and sea evacuation points, emergency contact details, as well as maps, images and GPS coordinates of evacuation craft, meeting points, and safe houses. In ten organisations, typical of all three industries, risk 
evaluations addressing context-specific details were undertaken for specific cities as well as countries. Most organisations also customised contingencies to cope with perceived inadequacies in host institutions (e.g. multiple evacuation routes and safe house options in case of emergency).

3. Collaborating, not competing: Arguably the strongest indication of these organisations' investment in expatriate safety and security comes from the extent of collaboration in which they chose to engage. Twelve of the 15 organisations in which staff could be interviewed participated in semi-formal national or international networks that discussed and exchanged safety/security knowledge. Pertinently, however, none of these networks included organisations from outside the sector. Collaboration was most evident in the IAD sector. Policy documents and interviewees cited publicly available information from multiple think tanks, policy institutes, and interest groups. Ad-hoc Security Management Teams, convened in-country as a crisis begins escalating, as well as permanent networks of security experts were used to share knowledge across the sector.

In a similar vein, $M \& R$ organisations commonly reviewed crisis plans against those of international and regional bodies, leading to the sharing of formalised 'standards.' The sector also had a practice of sharing elaborate in-house training and diagnostic activities, including live military-style scenarios involving affiliated operations ('It's quite clear that there's an appetite to share', R5). The sector has gone as far as developing accredited training programs that facilitate within-sector staff mobility. Likewise, media firms have begun offering expatriates standardised industry-specific training, and a recent collaborative, industry-wide initiative led to formal mediaspecific hostile environment training being established.

A distinctive aspect of this collaboration is that it tended to over-ride competition between organisations in the same sector. All 9 interviewees from the M\&R sector spoke about their experiences and willingness to share resources, information and HR practices with others in the 
sector ('It's one area where you're not bound by industry secrecy', R4). Similarly, a HR manager from the media sector explained that they:

... never collaborate on writing or legal (issues), but in the case of safety, it's safety before competition. We'll suspend competition for safety (M3).

\section{Three sector-specific philosophies for managing expatriate safety and security}

Against this backdrop of commonalities and comprehensiveness, our analysis also led us to articulate three sector-specific approaches to managing the safety and security of expatriates in hostile destinations. Each involved a system of HR practices underscored by a central philosophy, shared to varying degrees by organisations in the sector and which served as key points of between-sector differentiation (Table 3). The approach of organisations in the M\&R sector is 'regulatory' - highly structured, formalised, licence-driven, and heavily regulated. We label the media industry organisations' approach as 'informal mentoring', intentionally informal, heavily person-based, relying on the tacit know-how of key individuals (expatriates and HCNs) and shaped distinctly by occupational identity and their (primarily in-country) community of practice. The IAD sector's approach is designated as 'empowering,' focused on building organisational culture and capacity that is trained, empowered and nestled within support received from host communities.

1. Mining and Resources. In the M\&R sector's 'regulatory' approach, safety and security onus rests on all operating personnel, enforced by strong CEO support and led by centralised security teams of former military, police and emergency services workers, complemented by incountry managers. Licensing, regulation and the tightly-coupled nature of their operating systems imbue this sector with an imposed 'policing' emphasis; comprehensive, documented, and externally verifiable. Several firms, for example, require expatriates in specific locations to have seven days' emergency food and water provisions and a 'grab' bag of essential items (cash, 
passport etc). Mine sites typically have their own local evacuation plans, security policies, health and safety team, codes of conduct, and even hospitals. Housing expatriates in gated compounds as a means of separating them from the local community is common; cultural awareness training linked to expatriates' safety and security is less so. In general, non-essential interaction between expatriates and HCNs outside work is discouraged and mitigated through a policy of separation rather than education ('No-one leaves camp after 10:00 at night, drug and alcohol policies (are) enforced ...' R11, interview). Training, formally accredited and thus transferable, aims to verify hazard and crisis competence rather than improve cultural awareness. In short, crisis management is strategically important and part of the fabric of these organisations. The cost is considerable (R1, R2, R11 interviews) but willingly borne by these firms, which have substantial financial capacity and unwavering conviction that such cost is a necessity.

2. Media. While the approach of organisations in this sector is more variable than in the other two, the hallmark of the media industry is its deliberately individual-centred, 'informal mentoring' approach. Formal policies are comparatively ad-hoc, and the nascent tendency towards policy formulation continues to be countered by the remarkably strong, individualistic occupational culture of news journalism. These individuals make decisions about, for example, whether to travel with an organised security convoy, or to deploy less obtrusively and thus be less formally protected. In-country safety and security rests largely with the individual, founded in experientially-gained knowledge from on-the-job observations and semi-formal discussions with more experienced colleagues, HCNs or desk editors (usually former expatriates). In this regard, the expatriates' informal community of practice is a prominent influence on their decisionmaking, carrying greater credibility than formal organisational policies. Thus, the networks, local informants and 'street smarts' of individual journalists and their mentors become critical to their safety and security. This approach, which positions interpersonal relationships with HCN 
informants and confidants as a necessity to be encouraged, can be contrasted with the M\&R attitude of quarantining expatriates.

Consistent with the informal approach of this sector, ad-hoc person-focused and experience-based teaching, akin to a journey-'man' or mentor-protégé relationship still comprises a large part of expatriates' pre-departure 'orientation.' Post-crisis support also reflects the sector's informal, evolving approach.

Our findings suggest that, above all, the professional culture predisposing foreign correspondents toward independence and enduring hardship ('When everyone else is flying out of a crisis zone, the journalists are flying in', M4 interview) remains dominant (Feinstein, 2006). This was exemplified most strongly by an anecdote shared by a foreign correspondent who had been evacuated from a conflict zone for a period of rest; soon after returning home a white feather, recognised within the sector as a symbol of cowardice, was anonymously posted to his home letter box.

3. International aid and development. The most prominent feature of the sector's 'empowering' approach is organisations' efforts to build-in awareness of, and capacity for, safety and security management. This multifaceted commitment is oriented toward developing a culture in which staff are trained and empowered to be pro-active in assuming responsibility for the safety and security of themselves, others, and the organisation.

Central to the culture-building endeavours is compulsory training for all staff (including non-operational and casual staff) that emphasises safety awareness, decision making, and personal responsibility. Expatriates are expected to be proactive in two ways: via responsibility that 'our individual actions affect the safety and security' of everyone (A4, policy document), and by monitoring and sharing safety-related information 
Underpinning this approach is the importance placed on integrating expatriates into their host communities. This is the only industry to explicitly view expatriates' assimilation in the local community as 'a preferred security strategy' for the individual (A3, policy document), and 'by extension, the reputation of [the organisation] itself' (A4, policy document). To this end, improving cultural awareness, modifying behaviour and developing strong relationships within the host community, are central features of expatriates' security agenda.

This sector's embedded, community-founded, resource-constrained, empowering approach contrasts markedly with M\&R's licensing imperative, formalised qualification accreditation, overtly coordinated safety operations, and seemingly open-ended resourcing of hazard/emergency management. Flowing from this, the tendency toward an 'acceptance' approach (Fee \& McGrath-Champ, 2016) differs from M\&R firms' preference for a 'protection' strategy (van Brabant, 2001), focusing on reducing vulnerability through protection devices and barriers. The media sector's glimmers of growing training and policy systematisation sit juxtaposed with the individualism of journalists' occupational identity and the on-going necessity of embedded, locally-attuned knowledge and information. The generally sporadic placement and short-term presence of media journalists in host locations limits 'acceptance strategy' opportunities while simultaneously defying the development of comprehensive prescriptive systems, yielding a distinctive policy and practice mix presently in a state of transition. 


\section{Discussion}

We focus our interpretation by offering tentative explanations for the patterns documented in the Results section, and articulate a series of testable propositions that link the practices of internationally active organisations, via institutional theory, with the empirical results of our investigation.

\section{Sector isomorphism and legitimacy-seeking behaviour}

Arguably the most prominent finding is the unified pattern of philosophies and practices that emerged at the sector level, and the related between-sector differences. The three distinct philosophies (regulatory, informal mentoring, and empowering) represent starkly different responses to (host-country) institutional environments with similar conditions. We note that this difference is particularly prominent in relation to legitimacy-dependent threats emanating from host communities. For instance, IAD organisations' explicit framing of HCNs as sources of information, support and protection can be contrasted with $M \& R$ organisations' tendency to define HCNs as avoidable threats.

While multiple interpretations are possible, institutional theory leads us to propose that these configurations may reflect pragmatic choices an organisation makes about the form of legitimacy that best suits the sector-specific features of its work and its relationships with host communities (Kostova et al., 2008). To explain, organisations like those in the IAD sector, whose core business produces effects that are generally perceived as being favourable for the local community, have a higher chance of achieving legitimation from relevant host stakeholders provided this 'positive externality' is acknowledged by host institutional actors (Fast, 2014). We term this intrinsic legitimacy, whereby organisations' activities are perceived as congruent with the interests of a large proportion of local stakeholders, and as contributing directly or indirectly 
to the local field. On the other hand organisations like those in the M\&R sector whose activities serve predominantly the interests of non-local constituencies must resort to ad hoc actions aimed at demonstrating (either rhetorically or factually) compliance with local norms (O'Faircheallaigh, 2013). In these cases, extrinsic legitimacy must be achieved by means of specific legitimation strategies, since the activities of the organisation are neither aligned nor beneficial for the majority of local constituencies (Newenham-Kahindi, 2011).

A second feature influencing these organisations' practices relates to the actual need for host legitimation based on the extent to which organisations operate interdependently with host institutional actors. Industries like $\mathrm{M} \& \mathrm{R}$ enable expatriates to operate autonomously, in relative isolation from host social environments. In such circumstances, technologies, know-how and practices can, if desired, be readily imported to create 'self-contained' task environments requiring minimal levels of host acceptance and relatively weak isomorphic pressures from local institutions (Perrow, 2011). In contrast, sectors like IAD and media require organisations to actively interact and engage with the host field to achieve their core 'business.' This is not just an issue of higher exposure to local institutional forces, but also of higher legitimation requirements, since these organisations must actively collaborate with locals and integrate practices with local conditions in order to succeed. These features open the organisation to normative isomorphism (DiMaggio and Powell, 1983) via routines and approaches more inclusive of local input, and thus are oriented to seeking a higher level of legitimation.

Combining these dimensions, we propose a tentative $2 \times 2$ framework presented in Figure 1 that articulates four possible legitimation 'spaces' for preserving expatriate safety and security in hostile environments. These are based on two overarching dimensions: the extent to which the organisations' operations may be perceived as congruent with interests of host institutional actors 
(intrinsic/extrinsic legitimacy), and the extent to which the organisation needs to work interdependently with host institutional actors (high/low host interdependence).

\section{INSERT FIGURE 1 ABOUT HERE}

We expect organisations with high intrinsic legitimacy and high host interdependence (quadrant 2 in Figure 1) to be best placed to capitalise on host-country legitimacy in ensuring expatriate safety and security by being highly sensitive to local institutional conditions and exploiting the goodwill from their positive contribution to the local community. For these organisations, the risk of legitimacy-dependent threats is low, and knowledge-dependent threats can be offset through cultural and contextual awareness (e.g. selection, training). The IAD sector's 'empowering' approach is an example of this. In contrast, organisations with low interdependence and extrinsic legitimacy (quadrant 3) confront challenges achieving host legitimacy. In this space, 'separation' approaches typical of M\&R organisations in our study may be rational and efficient responses that minimise exposure to legitimacy- and knowledgedependent threats.

More problematic is the case of organisations whose activities are not intrinsically legitimate from the perspective of host institutions but which still need high host interdependence to operate (quadrant 4). This may be the case for the international media organisations in our study. For these organisations, the high cost of acquiring 'blanket' legitimacy may lead them to deploy a more agile position that enables individual expatriates to negotiate the level of host legitimation (in the form of personal social capital) that is necessary for their operations. Such an approach requires high levels of tacit knowledge and local expertise to avoid knowledgedependent threats, and so may lend itself toward the informal mentoring approach evident in media organisations. 
Finally, quadrant 1 represents an 'ideal' space where intrinsic legitimacy is feasible but legitimacy needs are actually low. While no organisations in our study fell into this category, one example may be faith-based organisations operating in destinations that are receptive to the core principles (e.g. Catholic missionaries in predominantly Catholic countries).

On the basis of the preceding discussion and the framework in Figure 1 we make the following proposition:

Proposition 1: The expatriate safety and security approaches used by organisations in hostile environments will be determined, in part, by the nature of the organisations' interactions with host institutions; specifically, the degree of interdependence and the perceived local externalities that are created in the performance of their business.

\section{The 'hostility' of uncertain institutional environments}

While the preceding discussion seeks to explain between-sector differences, the question of what institutional forces have contributed to the distinctive similarities in each sector is more complicated. An overwhelming picture that emerged from our analysis, and confirmed by interviewees, was the willingness of organisations to commit substantial time, energy, resources and effort well beyond 'standard operating procedures' to ensure expatriates in hostile environments were safe. All 28 organisations exhibited a strong foundation of normative duty of care, exemplified in Table 2, that exceeds the breadth and depth of practices evident in studies of 'mainstream' multinational corporations across several decades (Claus \& Giordano, 2013; Digh Howard, 1991; Harvey, 1993). As our results show, much of this energy focused on understanding and seeking to mitigate on-the-ground conditions in the host environment via collating and sharing local intelligence, and customising responses to this (Table 2).

We propose that these measures represent organisations' responses to the uncertainty associated with perceived elevated threat to expatriates emanating from the (hostile) host 
institutional environment. From an institutional perspective, the lack of robust formal institutions such as stable political and legal systems and reliable social welfare infrastructure, combined with organisations' relative unfamiliarity with host-countries' informal institutions (i.e., the safety and security 'liability' of foreignness), represent highly uncertain environments and make expatriates vulnerable to all three types of threats (infrastructure-dependent, legitimacydependent, knowledge-dependent). Viewed this way, organisations' use of mechanisms like sourcing copious amounts of local knowledge, elaborate and customised security plans, and sharing information with competitors, represent efforts to offset the ambiguity emerging from the generally weak and unfamiliar host institutional environments. Consequently, we propose:

Proposition 2a: In order to support the safety and security of expatriates in hostile environments, organisations will seek to overcome perceived institutional weaknesses by employing practices that go beyond minimum 'duty of care' requirements.

Proposition 2b: In order to support the safety and security of expatriates in hostile environments, organisations will seek to overcome perceived institutional weaknesses by investing in highly customised and information-intensive HR practices.

Beyond this, our analysis suggests an intricate mix of industry-dependent institutional forces also shape organisations' responses. The professional cultures that dominate the industries (normative forces) are prominent in all three sectors. In news media, foreign correspondents' reputation for combining independence and resilience with professional camaraderie (Feinstein, 2006) was strongly evident in our data and suggests a highly institutionalised domain (DiMaggio \& Powell, 1983). Likewise, the core principles and motivations of IAD professionals, including their emphasis on host community empowerment and development, were also evident in the approaches preferred by the sector (Fast, 2014; Fee \& McGrath-Champ, 2016).

However, other institutional forces were also apparent and acknowledged by interviewees. For instance, interviewees from the $M \& R$ sector confirmed that State licensing/regulatory 
requirements and trade union activity arising from incidents in home-country contexts constituted strong coercive forces (DiMaggio \& Powell, 1983). In the IAD sector, coercive influences from funding bodies that specify minimum organisational safety and evacuation capabilities were identified as increasingly powerful. In the media sector, despite occupational resistance by expatriates in the field, greater awareness of welfare issues for expatriates have been prompted by fatalities, duty of care insurance, and legal counsel. Recent major crisis events were also acknowledged as important determinants in that sector. It was also apparent that in all three sectors the high degree of within-sector staff mobility - facilitated in M\&R by accredited training programs - contributed to strengthening similarities in via normative forces (DiMaggio \& Powell, 1983).

In short, isomorphic tailwinds for these organisations comprised a complex mix of path dependence, professional culture, and stakeholder engagement, all of which contributed to the idiosyncratic sector approaches. From this we propose that:

Proposition 3: In relation to expatriate safety and security in hostile environments, sector- and industry-based differences emerge from different prevailing institutional forces.

\section{Sector homogeneity and collaborative behaviour}

Institutional theory posits that mimetic isomorphism typically emerges from competition between organisations (DiMaggio \& Powell, 1983). Indeed, for most corporate practices conformity within a sector is attributed primarily to intensive competition-driven benchmarking and imitation (Farndale \& Paauwe, 2007). However, even though HR practices reflect firm-specific competencies and organisational knowledge (Clark \& Lengnick-Hall, 2012), in hostile environments this does not seem to be transferred to expatriate safety and security practices. In fact, our results show that these practices are more aligned with shared human values and driven 
by genuine welfare issues, evident in sharing/collaborating on these issues rather than competing. One theoretical explanation for this 'consented mimicry' may relate to legitimacy spillover, whereby counterproductive actions of one organisation may taint perceptions of legitimacy toward all organisations that are seen to be alike because of their similarity on salient features (Kostova \& Zaheer, 1999). For instance, an incident at a mining facility or a death of an aid worker has the potential to hamper operations of all similar organisations in the region (Fast, 2014). Thus, by sharing information organisations may be acting to minimise potential negative impacts on their own expatriates by assisting other firms within their sector.

A second way our findings are inconsistent with institutionalism is via the extensive incountry networking and information sharing of these organisations, which contrasts with the limited inter-organisational contact and subsequent weak organisational fields that are believed to characterise internationally active organisations (Kostova et al., 2008). While alternative explanations are possible, the practice of formal and informal information sharing networks appears to have been a mechanism for offsetting uncertainty provoked by the weak host institutions (Kostova \& Zaheer, 1999). In short, hostile environments appear to encourage rather than deter inter-organisational contact, even in circumstances that make this challenging (e.g. limited communication infrastructure). It is likely that the 'cauldron' of the local conditions and perceived proximity of particular types of threats may help to forge a more collaborative, rather than competitive, mindset in the same way that external economic threats can coalesce industrylevel collaborations. One outcome of these networks is the strengthening of the organisational field through socially constructed cognitive norms. On this point, it is worth noting that while almost all case organisations participated in this practice, no organisations networked or shared information with individuals or organisations from outside the sector. 
These findings go some way to addressing the question of which institutional pressures become most prominent during times of stress. Whereas 'formal' coercive (regulatory) forces are generally recognised as influencing HR practices most prominently (Ferner, 1997), the hostile environments experienced by the case study organisations appears to have given prominence to a form of consented mimicry. Our final proposition, therefore, is:

Proposition 4: In relation to expatriate safety and security, the organisational fields of internationally active organisations in hostile environments produce isomorphic forces that tend to emerge from collaborative rather than competitive mimetic forces.

\section{Theoretical implications}

Our study extends earlier empirical research (Fee \& McGrath-Champ, 2016) in several important ways. First, our empirical materials collected across multiple sectors allow the mapping of clear between- and within-sector patterns of HR practices. Indeed, arguably the most prominent implications from the data relate to the clear sectoral differences in expatriate safety and security practices. All 28 organisations have experience managing expatriates in hostile settings and strong internal and external incentives to mitigate and quickly resolve crisis events. Yet three distinct approaches exist, reflecting a complex interplay of isomorphic influences such as the nature and legitimacy of the core business, occupational norms, and external factors like exposure to regulators or benefactors. In short, when it comes to expatriate safety and security practices, industry does appear to matter. While research in domestic contexts has identified industry-level patterns in several HR practices, including occupational health and safety (Bjerkan, 2010), international research in this domain has overlooked the potential for expatriates' industry to predict salient outcomes like perceived stress levels (Bader \& Berg, 2013) or sensitivity to threats (Bader, 2014) when working in high risk locations; our research foregrounds its importance as an explanatory variable in future studies. Pertinent to this, we also introduce the notion of 
'legitimating space' - a product of an organisations' perceived externalities and interdependence with the host community - as a metaphorical landscape within which an organisations' expatriate safety and security approaches may flourish or flounder.

As well as expanding descriptive accounts reported in earlier studies, the use of institutionalism as a theoretical lens allows us to posit a series of testable propositions explaining these patterns. Specifically, unlike earlier studies which describe in detail the patterns of HR policies and practices of hazard-exposed organisations (Fee \& McGrath-Champ, 2016), our theoretically-grounded propositions elucidate the HR practices and configurations deployed by the sample organisations. In combination with Figure 1, they provide a theoretical foundation that begins to map the relationship between the HR practices and the institutions that either heighten or mitigate the threats to personal safety and security. In doing so, we introduce theoretical underpinnings to both explain the results of earlier studies (Fee \& McGrath-Champ, 2016), and advance understanding of strategic HR choices beyond 'acceptance' and 'protection' approaches to safety and security (van Brabant, 2001) to incorporate the way that these strategies interact with hostile (and complex) institutional fields.

Building on this, by foregrounding the social construction of the legitimation process (Figure 1), our theorising reinforces the importance of symbolic practices and a deep understanding of the nuances of the host institutional context (Gherardi, 2006). By highlighting interactions between internationally active organisations and their host communities as an important consideration in understanding expatriate safety and security approaches, our study balances earlier work that emphasises the role of an organisation's (internal) culture in solidifying a coherent safety and security platform (Fee \& McGrath-Champ, 2016). This would seem to be especially relevant given the complex genealogy of threats that expatriates confront; notably, 
those derived from socially constructed realities (legitimacy-dependent threats), or the strongly relational elements inherent in knowledge-dependent threats.

To the extent that these relationships are dynamic, we would expect to see organisations respond by taking steps to either 'manage' these relationships (e.g. encouraging greater intrinsic legitimacy) or to adjust their expatriate safety and security approaches. For instance, evidence that organisations in the IAD sector appear to be using protective security approaches more frequently in recent years (Fast, 2014; Fee \& McGrath-Champ, 2016) may reflect changing perceptions in some host communities about the legitimacy of their work (from positive to negative externalities; hence a shift from quadrant 2 to quadrant 4 in Figure 1). Similarly, the evidence we document about the formalisation of practices within large media organisations may reflect decreasing interdependence with host actors (quadrant 4 to quadrant 3), perhaps due to technological changes and/or increasing use of freelancers. Used this way, Figure 1 represents not just a tool to map and understand the HR practices of internationally active organisations, but a framework for anticipating how changing institutional dynamics may affect these organisations' HR practices. These findings are consistent with the notion that the level of mutual dependence between fields affect the likelihood that actors in both fields will collaborate in creating new shared institutional practice (Furnari, 2016).

Beyond this, our results provide impetus for a reassessment of how the practices of internationally active organisations are configured to their complex institutional environments. Challenging earlier assertions (Kostova \& Zaheer, 1999) we found that, in hostile environments, mimetic isomorphism can emerge as a form of consented mimicry (rather than competitive isomorphism), and that organisational fields can be strengthened rather than weakened (proposition 4). To some extent these findings may reflect the discretionary freedom that internationally active organisations have to respond to their institutional environments (Kostova 
\& Zaheer, 1999). The results, however, do point to the benefits of studying organisationinstitution interactions in extreme conditions like those presented by hostile environments. At the same time, this may also reflect a broader tension between 'top down' formal policies, on the one hand, and emergent practices stemming from professional communities. The practices and policies of the case study organisations suggest that the relative influence of formal 'authorities' may be mediated by the relative 'tightness' of systemic interdependence between policies, actions and consequences (Orton \& Weick, 1990; Perrow, 2011) characterising different types of organisations. Our analysis highlights that the different practical modes of dealing with hostile environments are not determined by universal good practices or by objective characteristics of the dangers but emerge from an interaction between materiality (e.g. types of threats, technology at hand), institutional forces (e.g. isomorphism, pursuit of legitimacy) and the relative weight of organisational and community-of-practice influences. More specifically, it shows how environmental dangers add to the existing (high) level of institutional complexity that internationally active organisations face. The practical solutions they develop when coping with this complexity contribute to transformation in field-level logics (Smets \& Jarzabkowski, 2013) shaping different industry-specific institutional approaches to safety and security. As such it shows how embedded agency (Garud, Hardy, \& Maguire, 2007) operates at the intersection of different institutional fields, and thus contributes to a more nuanced picture of inter-field institutional transformation (Furnari, 2016).

\section{Practical implications}

At a practical level, the unifying features in Table 2 represent, we posit, a baseline of HR practices that internationally active organisations in hostile (and non-hostile) environments could 
benchmark. These findings refine and support - but also give credence to the cross-sector transferability of - a core set of 'hostile-exposed' practices (Fee \& McGrath-Champ 2016).

Yet our results show that these practices alone are insufficient. While they represent mitigating responses to the perceived threat and uncertainty of locations deemed as hostile, they fail to take into account how the patterns of interaction and interdependence with host institutions lead organisations to curate divergent configurations of practices. In this regard, Figure 1 provides a framework for understanding how the characteristics of internationally active organisations might determine the approach, and related suite of HR practices, that best enables them to protect their expatriates. Organisations producing positive externalities (quadrants 1 and 2) can benefit from the goodwill imbued in their operations by using host institutional actors as resources of information and protection thus increasing legitimacy. These firms can reinforce their philosophies by ensuring their positive intentions are understood and accepted by local stakeholders, and are deployed in culturally- and socially-sensitive ways. On the other hand, firms whose operations result in primarily extrinsic externalities may choose to direct resources toward minimising legitimacy- and knowledge-dependent threats (e.g. quarantining expatriates in gated compounds) or to seek to make attitudes of HCNs more favourable by, for instance, promoting the ways in which their operations benefit host institutional fields. Importantly, the framework makes clear that a one-size-fits-all solution to expatriate safety and security may not work. Rather, organisations must understand, and take advantage of, the various institutions emanating from the sector, professions and host countries in which their activities exist. Our findings therefore challenge the wisdom - from our experience common in the mainstream business community - of relying entirely on outsourced service providers to manage expatriates' safety and security via off-the-shelf solutions. 
The framework also provides a template for understanding the complexity of legitimacyseeking practices used by internationally active organisations when it comes to expatriate safety and security. Of pertinence is the need for these organisations to juggle legitimacy demands from geographically and culturally diverse groups of stakeholders (Kostova et al., 2008), all of which may differ in their interests in expatriate safety and security and perceptions about the organisation's externalities. We found tensions emerging in organisations from all three sectors that may be reflective of this. The IAD sector, for instance, faces pressure from some donors for a more hardened 'protection' approach to security (van Brabant, 2001) that is at odds with, and would likely undermine, the acceptance approach that underpinned the organisations' shared philosophy (Fast, 2014). We also heard accounts from informants in news media organisations about resistance of more experienced foreign correspondents to change emerging from the top (following crises like those of 11 September 2001). Such patterns appear consistent with isomorphic resistance that has been documented by institutional theorists (Ramanath, 2008). Competing demands like these may be explained as contrasting perceptions among stakeholders about the nature of the threat stemming from the organisations' externalities. Such differences of perspective highlight the need for organisations to collect evidence about how their operations are perceived by host institutional actors, an information activity that currently none of the organisations in our study undertake with any vigour. At a minimum, devising an appropriate expatriate safety and security approach requires organisations to be cognisant of how their operations are viewed by, and interdependent with, salient host institution actors. In turn, we suggest that this necessitates a base level of in-house expertise in host-culture awareness, perception monitoring, perception management and/or symbolic image building by associating with other bodies that have higher levels of legitimacy (Kostova et al., 2008). 
From this platform, Tables 2 and 3 plus Figure 1 indicate areas where organisations - and HR departments in particular - might focus efforts to develop greater awareness and expertise, and consequently play a more prominent role in supporting expatriate safety and security. The results may also assist organisations to diagnose strengths and weaknesses, or to meld key crisis management operations with broader strategic objectives. In a similar vein, our results hint at opportunities for across-the-board improvements by increasing cross-sector knowledge and resource sharing. International HR managers may be well positioned (Welch \& Welch, 2012) to instigate discussions with counterparts from different sectors about the possibility of formal or informal exchange of information, resources, policies, or programs (e.g. training modules) as a means of cross-fertilising knowledge and achieving economies of scale.

\section{Limitations and future research}

Like all studies, the research we report here has limitations that constrain the transferability of the results, most notably the need for deductive verification of our propositions. Beyond this, broadening the range of sample organisations and operating environments will enable more nuance regarding the features we have unveiled. In particular, expanding empirical investigations to encompass additional sectors - including others that operate in hostile locations (e.g. government diplomatic corps) - may lead to more thorough typologies of industry responses that build on the work reported here. Similarly, while we actively sought interviewees able to provide diverse perspectives, research that includes informants with other experiences (e.g. pre-departure expatriates, external government stakeholders, specialist service providers, host-country community members) is worthwhile. Moreover, while the parent countries of our case study organisations were varied, all were based in developed nations from the 'Global North'. Thus, studies that investigate the practices of internationally active organisations from developing 
countries, where similarities between home and host institutional environments may be stronger, might unearth new insight.

Beyond the sample, our theoretical lens for this study (institutional theory) led our analysis to focus on external factors. New understanding into how and why expatriate safety and security practices are configured the way they are is likely to emerge from a range of alternative, equally valid, perspectives. On this issue, we make a final observation. Our focus for this special issue article was on hostile environments, and how the various institutional forces influence the HR practices of internationally active organisations. However, it is pertinent that the operations of internationally active organisations themselves are not always neutral and may, in fact, create environmental risks. That is, through their operations, practices and attitudes, organisations may introduce threats to otherwise benign institutional environments that create or exacerbate hostility for local communities (Baram, 2009). This may be especially true of economically, socially and politically fragile contexts, susceptible to the introduction of activities that pose physical, environmental, political, and/or social hazards (e.g. activities that disrupt biological equilibrium, challenge the political status quo, or reflect different cultural values). In this regard, the practice of internationally active organisations in enacting hostile environments, while not addressed here, is worthy of further investigation. 


\section{References}

Bader, B. (2014). The influence of terrorism on expatriate performance: a conceptual approach. The International Journal of Human Resource Management, 25(4), 539-.

Bader, B., \& Berg, N. (2013). An empirical investigation of terrorism-induced stress on expatriate attitudes and performance. Journal of International Management, 19(2), 163175.

Bader, B., \& Schusterb, T. (2015). Expatriate social networks in terrorism-endangered countries: An empirical analysis in Afghanistan, India, Pakistan, and Saudi Arabia. Journal of International Management, 21(1), 63-77.

Baram, M. (2009). Globalization and workplace hazards in developing nations. Safety Science, 47(6), 756-766.

Bernstein, J. (2011). Manager's Guide to Crisis Management. New York: McGraw-Hill.

Bjerkan, A. M. (2010). Health, environment, safety culture and climate - analysing the relationships to occupational accidents. Journal of Risk Research, 13(4), 445-477.

Chien, G. C. L., \& Law, R. (2003). The impact of the severe acute respiratory syndrome on hotels: A case study of Hong Kong. International Journal of Hospitality Management, 22(3), 327-332.

Clark, K., \& Lengnick-Hall, M. L. (2012). MNC practice transfer: Institutional theory, strategic opportunities and subsidiary HR configuration. The International Journal of Human Resource Management, 23(18), 3813-3837.

Claus, L. (2009). Duty of Care of Employers for Protecting International Assignees, their Dependents, and International Business Travelers. Philadelphia, PA: International SOS.

Claus, L. (2010). International assignees at risk: Employers have a duty of care for workers around the globe. HR Magazine, February.

Claus, L. (2011). Duty of Care and Travel Risk Management: Global Benchmarking Study. Philadelphia, PA: International SOS.

Claus, L., \& Giordano, E. (2013). Global employer duty of care: Protecting the health, safety, security and well-being of employees crossing borders. In L. Claus (Ed.), Global HR Practitioner Handbook (pp. 280-299).

Cornwall, A., \& Brock, K. (2005). What do buzzwords do for development policy? A critical look at 'participation', 'empowerment' and 'poverty reduction. Third World Quarterly, 26(7), 1043-1060.

Crandall, W., Parnell, J. A., \& Spillan, J. E. (2010). Crisis Management in the New Strategy Landscape. Thousand Oaks, CA: Sage.

Cuddihy, M. (2016). Australian workers at engineering giant Macmahon kidnapped in Nigeria. Australian Broadcasting Corporation, (23 June). Retrieved from http://www.abc.net.au/news/2016-06-23/australian-south-african-mining-workerskidnapped-in-nigeria/7535308

Czinkota, M. R., Knight, G., Liesch, P. W., \& Steen, J. (2010). Terrorism and international business: A research agenda. Journal of International Business Studies, 41(5), 826-843. 
Deephouse, D. L. (1996). Does isomorphism legitimate? (includes appendices). Academy of Management Journal, 39(4). Retrieved from

Digh Howard, P. (1991). Circle of impact: HR professionals respond to war, riot, terrorism. Employment Relations Today, 18(1), 29-38.

DiMaggio, P., \& Powell, W. W. (1983). The iron cage revisited: Institutional isomorphism and collective rationality in organizational fields. American Sociological Review, 48(2), 147160.

Donaldson, L. (2001). The Contingency Theory of Organizations. Thousand Oaks, CA: SAGE.

Dul, J., \& Hak, T. (2008). Case Study Methodology in Business Research. Burlington, MA: Butterworth-Heinemann.

Edmondson, A. C., \& McManus, S. E. (2007). Methodological fit in management and research field. Academy of Management Review, 32(4), 1155-1179.

Farndale, E., \& Paauwe, J. (2007). Uncovering competitive and institutional drivers of HRM practices in multinational corporations. Human Resource Management Journal, 17(4), 355-375.

Farquhar, J. D. (2012). Case Study Research for Business. Thousand Oaks, CA: Sage.

Fast, L. (2014). Aid in Danger: The perils and promise of humanitarianism. Philadelphia, PA: University of Pennsylvania Press.

Fee, A., \& McGrath-Champ, S. (2016). The role of human resources in protecting expatriates: Insights from the international aid and development sector. The International Journal of Human Resource Management, 1-26. doi:10.1080/09585192.2015.1137617

Fee, A., McGrath-Champ, S., \& Liu, H. (2013). Human resources and expatriate evacuation: a conceptual model. Journal of Global Mobility, 1(3), 246-263.

Feinstein, A. (2006). Journalists Under Fire: The psychological hazards of covering war. Baltimore MD: The John Hopkins University Press.

Ferner, A. (1997). Country of origin effects and HRM in multinational companies. Human Resource Management Journal, 7(1), 19-37.

Furnari, S. (2016). Institutional fields as linked arenas: Inter-field resource dependence, institutional work and institutional change. Human Relations, 69(3). Retrieved from

Garud, R., Hardy, C., \& Maguire, S. (2007). Institutional entrepreneurship as embedded agency: An introduction to the special issue. Organization Studies, 28(7), 957-969.

Gerring, J. (2007). Case Study Research: Principles and practices. Cambridge: Cambridge University Press.

Gherardi, S. (2006). Organizational Knowledge: The texture of workplace learning. London: Blackwell.

Gherardi, S., \& Nicolini, D. (2000). The organizational learning of safety in communities of practice. Journal of Management Inquiry, 9(1), 7-18. 
Gooderham, P. N., Nordhaug, O., \& Ringdal, K. (1999). Institutional and rational determinants of organizational practices: Human resource management in European firms. Administrative Science Quarterly, 44(3), 507-531.

Greenwood, R., Oliver, C., Sahlin, K., \& Suddaby, R. (Eds.). (2012). Institutional Theory in Organization Studies. London, UK: SAGE.

Harvey, M. G. (1993). A survey of corporate programs for managing terrorist threats. Journal of International Business Studies, 24(3), 465-478.

Institute for Economics and Peace. (2014). Global Terrorism Index: Measuring and understanding the impact of terrorism. Retrieved from http://static.visionofhumanity.org/sites/default/files/Global\%20Terrorism\%20Index\%20R eport\%202014.pdf

Kostova, T., Roth, K., \& Dacin, M. T. (2008). Institutional theory in the study of multinational corporations: A critique and new directions. Academy of Management Review, 33(4), 9941006.

Kostova, T., \& Zaheer, S. (1999). Organizational legitimacy under conditions of complexity: The case of the multinational enterprise. Academy of Management Review, 24(1), 64-81.

Kulik, C. T., \& Bainbridge, T. J. (2006). HR and the line: The distribution of HR activities in Australian organizations. Asia Pacific Journal of Human Resources, 47(3), 541-558.

Lepoutre, J. M., \& Valente, M. (2012). Fools breaking out: The role of symbolic and material immunity in explaining institutional nonconformity. Academy of Management Journal, 55(2), 285-313.

Lindøe, P. H., Engen, O. A., \& Olsen, O. E. (2011). Responses to accidents in different industrial sectors. Safety Science, 49(1), 90-97.

Maguire, S., \& Hardy, C. (2009). Discourse and deinstitutionalization: The decline of DDT. Academy of Management journal, 52(1), 148-178.

McPhail, R., \& McNulty, Y. (2015). 'Oh, the places you won't go as an LGBT expat!' A study of HRM's duty of care to lesbian, gay, bisexual and transgender expatriates in dangerous locations. European Journal of International Management, 9(6), 737-765.

Newenham-Kahindi, A. M. (2011). A global mining corporation and local communities in the lake Victoria zone: The case of Barrick Gold multinational in Tanzania. Journal of Business Ethics, 99(2), 253-282.

O'Faircheallaigh, C. (2013). Community development agreements in the mining industry: An emerging global phenomenon. Community Development, 44(2), 222-238.

Orton, J. D., \& Weick, K. E. (1990). Loosely coupled systems: A reconceptualization. The Academy of Management Review, 15(2), 203-223.

Perrow, C. (2011). Normal Accidents: Living with high risk technologies. Princeton, NJ: Princeton University Press.

Ramanath, R. (2008). Limits to institutional isomorphism: Examining internal processes in NGO-government interactions. Nonprofit and Voluntary Sector Quarterly, 38(1), 51-76. 
Raphael, B. (1986). When Disaster Strikes: A handbook for the caring profession. London: Unwin Hyman.

Rosenzweig, P. M., \& Nohria, N. (1994). Influences on human resource management practices in multinational corporations. Journal of International Business Studies, 25(2), 229-251.

Scott, W. R. (1995). Institutions and Organizations. Thousand Oaks, CA: SAGE.

Seale, C. (1999). The Quality of Qualitative Research. London: SAGE.

Smets, M., \& Jarzabkowski, P. (2013). Reconstructing institutional complexity in practice: A relational model of institutional work and complexity. Human Relations, 66(10), 12791309.

Suchman, M. C. (1995). Managing legitimacy: Strategic and institutional approaches. Academy of Management Review, 20(3), 571-610.

van Brabant, K. (2001). Mainstreaming the Organisational Management of Safety and Security: Humanitarian Policy Group Report 9. London: Overseas Development Institute.

Von Krogh, G., Rossi-Lamastra, C., \& Haefliger, S. (2012). Phenomenon-based research in management and organization science: When is it rigorous and does it matter? Long Range Planning, 45(4), 277-298.

Watson, G. W. (2005). Dimensions of interpersonal relationships and safety in the steel industry. Journal of Business and Psychology, 19(3), 303-318.

Welch, C. L., \& Welch, D. E. (2012). What do HR managers really do? HR roles on international projects. Management International Review, 52(4), 597-617.

Wenger, E. (2000). Communities of practice and social learning systems. Organization,, 7, 225 246.

Westney, D. E. (1993). Institutionalization theory and the multinational corporation. In S. Ghoshal \& D. E. Westney (Eds.), Organization theory and the multinational corporation (pp. 47-67). Basingstoke: Palgrave.

Yin, R. K. (2003). Case Study Research: Design and Methods, 3rd edn. Thousand Oaks, CA: SAGE.

Zhang, M. M., McNeil, N., Bartram, T., Dowling, P., Cavanagh, J., Halteh, P., \& Bonias, D. (2016). Examining the 'black box'of human resource management in MNEs in China: Exploring country of origin effects. The International Journal of Human Resource Management, 27(8), 832-849. 
Table 1: Industry source profile

\begin{tabular}{|c|c|c|c|}
\hline $\begin{array}{c}\text { Respondent organisation } \\
\text { characteristics }\end{array}$ & Mining \& resources & News media & $\begin{array}{c}\text { International aid \& } \\
\text { development }\end{array}$ \\
\hline \multicolumn{4}{|l|}{ Organisation characteristics } \\
\hline Number of organisations & 12 & 6 & 10 \\
\hline $\begin{array}{l}\text { Parent country of } \\
\text { respondent organisations }\end{array}$ & $\begin{array}{l}\text { Australia, Japan, } \\
\text { Netherlands, Norway, } \\
\text { Switzerland, UK, USA }\end{array}$ & Australia, UK, USA & $\begin{array}{l}\text { Australia, Germany, UK, } \\
\text { USA }\end{array}$ \\
\hline \multicolumn{4}{|l|}{$\begin{array}{l}\text { Number of expatriates (per } \\
\text { organisation) }\end{array}$} \\
\hline $\begin{array}{l}\text { - Average } \\
\text { - Range }\end{array}$ & $\begin{array}{l}1780 \\
60-3500\end{array}$ & $\begin{array}{l}296 \\
20-1200\end{array}$ & $\begin{array}{l}2250 \\
190-8600\end{array}$ \\
\hline Expatriate location/s & $\begin{array}{l}\text { Africa, Asia-Pacific, } \\
\text { Europe, Middle East, } \\
\text { North America, South } \\
\text { America }\end{array}$ & $\begin{array}{l}\text { Africa, Asia-Pacific, } \\
\text { Europe, Middle East, } \\
\text { North America, South } \\
\text { America }\end{array}$ & $\begin{array}{l}\text { Africa, Asia-Pacific, } \\
\text { Europe, Middle East, } \\
\text { North America, South } \\
\text { America }\end{array}$ \\
\hline
\end{tabular}

\begin{tabular}{|c|c|c|c|}
\hline Source Information & & & \\
\hline Policy documents & 59 & 9 & 104 \\
\hline $\begin{array}{l}\text { Interviews } \\
\qquad \quad \text { Number } \\
\qquad \quad \text { Respondents' roles }\end{array}$ & $\begin{array}{l}9 \\
6 \times \text { security/risk manager } \\
3 \times \text { HR manager }\end{array}$ & $\begin{array}{l}7 \\
2 \text { x manager (non } \mathrm{HR} \text { ) } \\
3 \times \text { HR manager } \\
2 \text { expatriate }\end{array}$ & $\begin{array}{l}11 \\
4 \times \text { security/risk manager } \\
2 \times \text { manager (non HR) } \\
\text { 1x HR manager }\end{array}$ \\
\hline $\begin{array}{l}\text { In-text organisation } \\
\text { reference }\end{array}$ & $\mathrm{R} 1-12$ & M1-6 & A1-10 \\
\hline
\end{tabular}

${ }^{1}$ Data relating to the 10 organisations in this sector have been used in prior published research (Fee \& McGrathChamp 2016). 
Table 2: Common expatriate safety and security practices used in hostile environments

\begin{tabular}{|c|c|}
\hline Common feature & Common characteristics \\
\hline Information intensity & $\begin{array}{l}\text { - Strategic use of multiple information sources } \\
\text { - Ongoing 'environmental scanning' of on-the-ground conditions } \\
\text { - Central internal clearinghouse to process and analyse data } \\
\text { - Triangulation of data sources and types }\end{array}$ \\
\hline Customisation & $\begin{array}{l}\text { - Customisation of HR practices, including recruitment and selection, to suit local conditions } \\
\text { - Compulsory in-country safety and security briefings } \\
\text { - Independent security evaluations for specific cities, sometimes at odds with home government } \\
\text { recommendations } \\
\text { - Customised evacuation procedures supported by comprehensive policies }\end{array}$ \\
\hline Collaboration & $\begin{array}{l}\text { - Formal and informal intra-sector networks to collaborate in response to threats, crises, and expatriate } \\
\text { safety and security issues } \\
\text { - Sharing of information among security personnel relating to expatriate safety and security, including } \\
\text { policies, training programs, and minimum standards }\end{array}$ \\
\hline
\end{tabular}


Table 3: Sample sector characteristics and expatriate safety and security practices in hostile environments (summary of differences by sector)

\begin{tabular}{|c|c|c|c|}
\hline & Mining and resources & Media & International aid and development \\
\hline $\begin{array}{l}\text { Sector } \\
\text { characteristics }\end{array}$ & $\begin{array}{l}\text { - } \text { Geographically remote and fixed } \\
\text { - Concentrated expatriate } \\
\text { deployments } \\
\text { - } \text { Relative isolation from host actors } \\
\text { - } \text { hapital intensive and inherently } \\
\text { - Highly standardised and tightly- } \\
\text { coupled operations }\end{array}$ & $\begin{array}{l}\text { - Small and dispersed expatriate } \\
\text { deployments } \\
\text { - Regular networking and interaction } \\
\text { with host actors but irregular work } \\
\text { patterns } \\
\text { - Opportunities for regular interaction } \\
\text { with expatriates in the sector }\end{array}$ & $\begin{array}{l}\text { - Variable placements often via embedding } \\
\text { expatriates in host communities } \\
\text { - Substantial interactions with and reliance } \\
\text { on host actors through capacity building }\end{array}$ \\
\hline $\begin{array}{l}\text { Overarching } \\
\text { philosophy }\end{array}$ & $\begin{array}{l}\text { Regulatory (compliance with } \\
\text { formalised standard) }\end{array}$ & $\begin{array}{l}\text { Informal mentoring (tacit knowledge- } \\
\text { exchange) }\end{array}$ & $\begin{array}{l}\text { Empowering (shared-responsibility based on } \\
\text { local knowledge) }\end{array}$ \\
\hline $\begin{array}{l}\text { Expatriate } \\
\text { screening criteria }\end{array}$ & $\begin{array}{l}\text { Technical competence, formal crisis } \\
\text { qualifications/accreditation }\end{array}$ & $\begin{array}{l}\text { Technical competence, inherent 'street } \\
\text { smarts' and experience }\end{array}$ & Technical competence, cultural intelligence \\
\hline Expatriate training & $\begin{array}{l}\text { Extensive, compulsory and multi-modal, } \\
\text { emphasising verification and portability }\end{array}$ & $\begin{array}{l}\text { Primarily informal mentor-protégé } \\
\text { exchange on the job from expatriates and } \\
\text { host-country nationals }\end{array}$ & $\begin{array}{l}\text { Extensive, compulsory and multi-modal, with a } \\
\text { strong focus on cultural awareness }\end{array}$ \\
\hline Expatriate housing & $\begin{array}{l}\text { Designated compounds to reduce } \\
\text { interactions with host communities }\end{array}$ & $\begin{array}{l}\text { Varied; based on recommendation from } \\
\text { incumbent and informants }\end{array}$ & Embedded in host community where feasible \\
\hline $\begin{array}{l}\text { Crisis management } \\
\text { procedures }\end{array}$ & $\begin{array}{l}\text { Comprehensive and formalised, well } \\
\text { resourced }\end{array}$ & $\begin{array}{l}\text { Ad hoc, negotiated between expatriate and } \\
\text { line manager }\end{array}$ & $\begin{array}{l}\text { Comprehensive and formalised, drawing on } \\
\text { expertise and goodwill from host community }\end{array}$ \\
\hline Post-crisis support & Externally-sourced from specialists & $\begin{array}{l}\text { Evacuee-initiated, informal, restricted by } \\
\text { occupational culture of 'endurance' }\end{array}$ & $\begin{array}{l}\text { Comprehensive psychological and medical } \\
\text { support from specialists }\end{array}$ \\
\hline
\end{tabular}


Figure 1: Framework of options for supporting expatriate safety and security (host interdependence and host externalities)

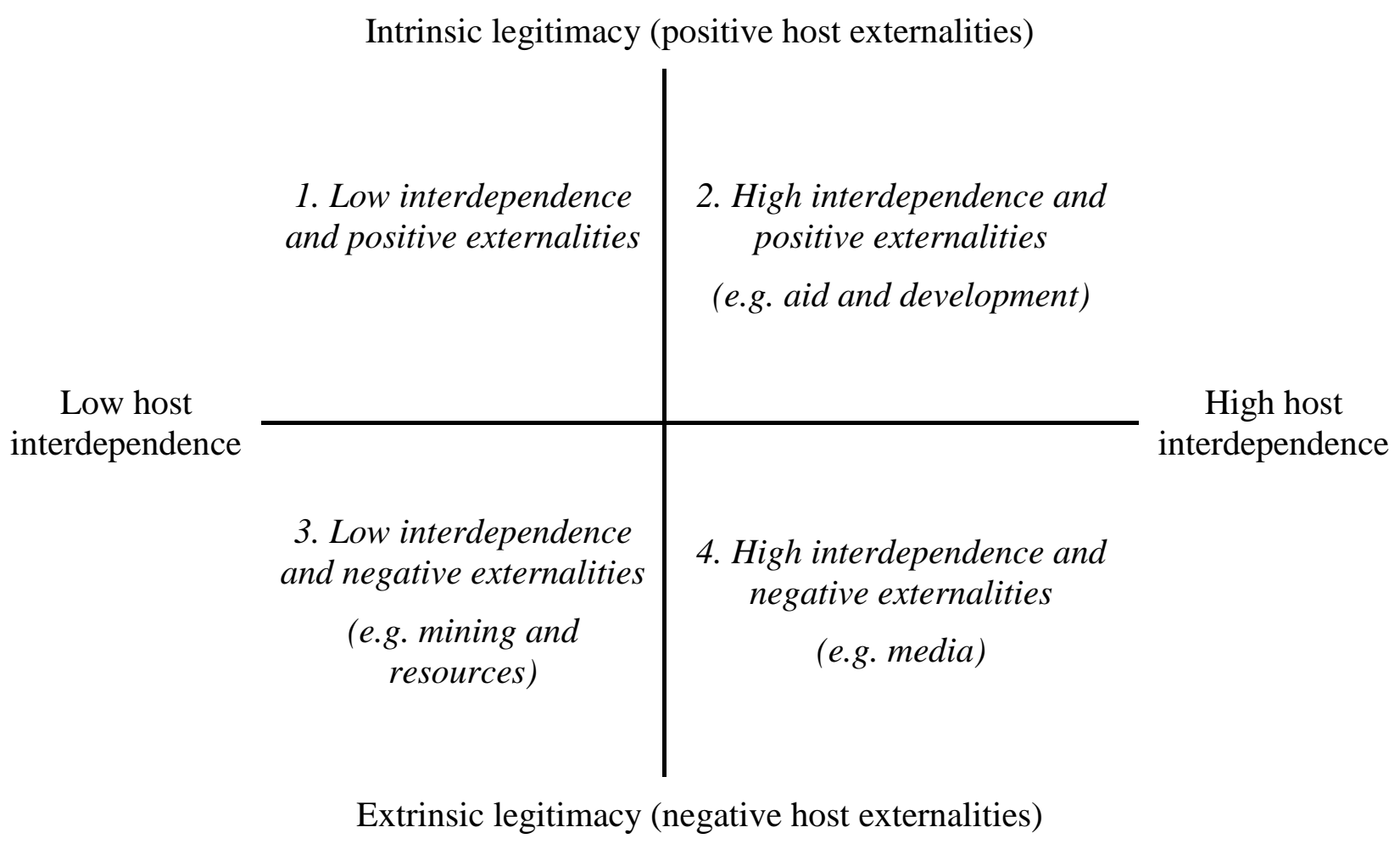

